\title{
Creativity and Its Discontents: Professional Ideology and Creativity in Architect Work
}

\author{
Alexander Styhre and Pernilla Gluch
}

\begin{abstract}
Architects are a professional group that is commonly associated with creative and aesthetic work and with strong professional norms, values and identities. While such shared norms and beliefs are positive overall in terms of being constitutive of professional subject-positions, an overemphasis on specific skills and qualities may also be regarded as a burden on members of the professional community. A study of a major Scandinavian architect office suggests that the perceived lack of creative and innovative thinking and accompanying dialogues and discussions among practising architects tends to produce cynicism and, to some extent, disappointment. As a consequence, professional ideologies may in some cases be out of joint with everyday work realities, and thereby to some extent produce expectations that are complicated to fulfil. Professional ideologies are thus both what integrates and consolidates a profession while at the same time prescribing ideal future scenarios for the professional community.
\end{abstract}

\section{Introduction}

$\mathrm{T}$ he concepts of aesthetic knowledge or sensible knowledge have been discussed in the organization theory literature, denoting a range of skills, capacities and know-how enabling thoughtful and credible practices in specific fields of expertise (Taylor \& Hansen, 2005; Ewenstein \& Whyte, 2007; Strati, 2007). Such fields of expertise are commonly regarded as being representative of the so-called 'creative industries' (Jeffcut, 2000; Caves, 2000; Dempsey, 2006), that is, a series of occupations and professions relying on perceptual and sensual skills as a central component of one's daily work. In Caves' (2000) view, the creative industries are based on the position that art (in the broadest sense of the term) has cultural virtues beyond practical utility - an 'art for art's sake' position, if you like - and workers in the creative industries are consequently tolerating lower wages, higher degrees of insecurity, and exposure to genuine uncertainty such as volatile and highly unpredictable market demand and the strong influence of expert opinions such as journalists and other commentators (see Menger, 1999; Dempsey, 2006). Work in the creative industries is in most cases highly specialized and demands credentials from schools and education programmes. In addition, being able to entrench a position in a creative field demands specific skills that at times are complicated to formalize or even to express verbally, that is, to demonstrate the ability of 'being creative', to have the skill of moving outside of what has been previously contrived and to present new ideas (Bourdieu, 1993). One such alleged creative profession is architect work. Architects need to master a series of activities that in many cases include the use of aesthetic knowledge, that is, knowledge that is complicated to express and formalize (Blau, 1984; Gutman, 1988; Cuff, 1991; Winch \& Schneider, 1993; Yaneva, 2005; Ewenstein \& Whyte, 2007; Unwin, 2007). At the same time, architect work is fundamentally collaborative and includes tight communication with various stakeholders including clients, contractors, and end-users (Andreu \& Oreszczyn, 2004; Ivory, 2004; Boland, Lyytinen \& Yoo, 2007). The profession of architects is therefore operating in the form that Jones et al. (1998: 398) refer to as a constellation, a specific form of organization wherein '[a] group of firms interact directly and reciprocally ... [and] coordinate their efforts for a complex service or product during a finite period of time'. Working in such a constellation makes it 
at times complicated to maintain the creative elements of the work. This paper reports a study of a major Scandinavian architect office and makes the claim that architects and other professional groups engaging in design work are concerned about their ability to maintain and develop their creative skills in the present economic regime.

The paper is structured as follows. First, the concepts of creativity and creative industries are discussed. Then the methodology of the study is described. Third, the empirical material is presented and, finally, some concluding remarks are provided.

\section{Creative Work and Its Features}

The concept of creativity is etymologically derived from the Indo-European root ker, 'to grow', which in turn is the basis for the Greek word khorus, 'youth', and the Latin Ceres, the 'Goddess of youth' (Schumann, 1993: 111). In the present economic regime, characterized by a strong belief in entrepreneurial activities and entrepreneurial spirit as the primary motor of the advanced global economy (see, e.g., Knight, 1921; Schumpeter, 1942), creativity is a highly praised capacity or resource and has consequently been subject to much attention in management studies (Amabile et al., 1996; Oldham \& Cummings, 1996; Amabile, 1997, 1999; Andriopoulos, 2001; Unsworth, 2001; Styhre \& Sundgren, 2005). For instance, Richard Florida (2002: 6) claims that 'access to talented and creative people is to modern business what access to coal and iron ore was to steelmaking. It determines where companies will choose to locate and grow, and this in turn changes the ways cities must compete'.

Other commentators, such as Osborne (2003), take a more sceptical attitude towards creativity as a source of social renewal and claim that the entire concept is having ideological overtones and that the insistence on the need for 'being creative' is easily becoming a form of morality - not a choice or a preference but an obligation. In this recent praise of creativity and the creative individuals, two specific groups have provided the principal voice, Osborne (2003: 508) claims, namely psychologists and managers. These are what Osborne (2003: 508) calls the 'ideologues of creativity'. Rather than endorsing the mainstream definition of creativity, Osborne (2003: 522) calls for what he refers to as 'a post-heroic conception of creativity', a theory of creativity that escapes hagiographic accounts of individual contributions and conceives of creativity as a historically contingent and situational concept that needs to be explained not on the basis of individual but rather collective action. Taken together, the concept of creativity remains largely contested; for some, creativity is in the true sense what advances humankind towards higher states, while for others, creativity is a mere ideological construct aimed at organizing and structuring society. To avoid polarizing creativity into either a good or a bad thing, a more tempered view may be that creativity is a concept that is useful to the extent that it is capable of capturing and denoting a set of tacit skills that are otherwise complicated to address. More specifically, a number of occupations and professions, ranging from gardeners to architects or plastic surgeons are mobilizing aesthetic skills that are, at the bottom line, based on creative capabilities. That is, the concept of creativity is useful from a pragmatic point of view because it helps us understand how certain occupational or professional groups are structuring and organizing their day-to-day work on the basis of principles and standard operating procedures that ultimately are derived from the idea of creativity.

Some industries are even defined in terms of their alleged innate creativity. For instance, the UK Department for Culture, Media and Sport issued a report in 1998 in which the "creative industries' were defined as follows: 'Those activities which have their origin in individual creativity, skill, and talent, and which have a potential for wealth and job creation through the generation and exploitation of intellectual property' (DCMS, 1998, 2001; see also Roodhouse, 2006: 52). Even though this definition is politico-administrative in nature and issued by the state bureaucracy, more academic attempts at defining creative industries make use of a similar vocabulary. For instance, Jeffcut (2000: 125) speaks of the creative processes in such industries accordingly:

[T] he creative process is sustained by inspiration and informed by talent, vitality and commitment (i.e., a need to create rather than to consume): this makes creative work volatile, dynamic and risk-taking, shaped by important tacit skills (or expertise) that are frequently submerged (even mystified) within domains of endeavour. Hence, the crucial relationship between creativity and innovation (i.e., the process of development of original ideas toward their realization/ consumption) remains unruly and poorly understood.

'Creativity', 'skill', 'talent', 'commitment' are thus the principal 'production factors' of the creative industries. Besides the circular argument - creative industries are based on 
creativity - equally the administrative and the academic account of creative industries are struggling to capture the very core of these industries, the 'core competencies' or the significant 'resources' or 'assets' to fashion the task in a strategic management theory vocabulary. Notwithstanding the problems associated with the definition of the creative industries, there are a number of organizational processes that needs to be managed in the creative industries. First, there is a need for individual creative skills, a term defined by Shalley and Gilson (2004: 36):

Creativity relevant skills can be defined as the ability to think creatively, generate alternatives, engage in divergent thinking, or suspend judgment. These skills are necessary because creativity requires a cognitiveperceptual style that involves the collection and application of diverse information, an accurate memory, use of effective heuristics, and the ability and inclination to engage in deep concentration for long periods of time.

In addition, a number of contributors emphasize, creative skills need to be complemented by creative leadership practices. Rather than being conventional (i.e., transactional) leaders, the creative leader is more of a consultant or facilitator, a charismatic and transformational leader capable of making the co-workers exploit the full scope of their innate talent (Rickards \& Moger, 2000; Mumford et al., 2002; Shin \& Zhou, 2003; Amabile et al., 2004). Basadur (2004) is representative of what Bryman (1992) calls the 'new leadership genre':

A creative leader induces others to focus the process and process skills on meeting their challenges. They become consultants or facilitators in the process of solving the challenges rather than giving orders or doing the work themselves. Having transferred ownership, they then help others to achieve their own goals. These creative leadership skills hardly fit with the traditional management style that most organizations employ, but they can be learned. (Basadur, 2004: 111)

A recurrent theme in the creativity literature is the need for both supporting creative co-workers while leaving much leeway for individual initiatives. This makes leadership practice in creative industries a delicate balancing of conventional, more authoritarian leadership and a more coaching attitude. Underlying all the concerns and worries about how to 'manage' the creative industries is the fact that, by definition, creativity is a rare thing, an exception in the day-to-day work in social reality. Creative work is for the most part routine work, work that is taking place along well-known routes and that is a fine-tuning of a set of skills and procedures that have been learned. What the co-worker in a creative industry is hoping for is a 'flash of brilliance' (in Miller's, 1999, terms) that may make them think in new ways, potentially positioning themselves as an extraordinary individual within a specific field of expertise. However, just as the professional scientist needs to be capable of pursuing a career with the intention of making a small and well-defined contribution to a narrow field (Weber, 1948), so must the co-worker in a creative industry be able to work long periods without engaging in what they regard as proper creative work. The ideology of creativity is then in contrast with the mundane matters filling the day-to-day work in supposedly creative industries. However, in, for instance, scientific work, following other principles than the more traditional creative industries (theatre, the arts, film production, etc.), creativity is an indispensable part of the work, yet most of the time is filled with other activities that scientists tend not to regard as being creative: scientists need to write research applications and take care of laboratory equipment. In a similar manner, artists have to negotiate with gallery owners and potential buyers and apply for scholarships, and fashion designers are spending substantial time correcting details in their collections, and so forth. The short and fickle moments of creative insights and creative activities are thus glimpses of light in a long night of non-creative work. In the case of architecture work, there is a similar distinction between on the one hand what is regarded to be truly creative and innovative work and the day-to-day work characterized by collaborations with clients and end-users, negotiations over qualities and costs of the forthcoming building, and significant amounts of noncreative routine work.

In their study of British architects, Cohen et al. (2005: 782) found that architects identify themselves with at least three distinct roles, namely as artists, business people and public servants. In the role of artists, architects are capable of using their full creative potential. The business people role is more oriented towards the management of the activities and the financial matters involved. Finally, the role of being a public servant is emphasizing the assignment to provide a qualitative built environment for the general public. Cohen et al. (2005) also found that a majority of the architects in their sample deplored the loss of creativity in their day-to-day work: 
Only six people in our sample [out of 42] described themselves as primarily involved in the creative process, and even they believed that they would have to give it up if they wanted upward progression in their organization. Our participants often discussed the creative aspects of work with a kind of sentimental longing. While acknowledging its importance in terms of architectural history and cultural heritage, on a day-to-day basis there was a recognition that it was often subordinated to more pressing, business concerns. (Cohen et al., 2005: 783)

This perceived relative loss of creative work did not mean, however, that the architects did not associate their profession with creative talents and skills. On the contrary, Cohen et al. (2005) argue, the architects in the sample continually '[d]escribed creativity as the legitimate core of architecture - its defining and differentiating feature':

As noted, for the majority, creativity was subsumed within other discursive frames, legitimated in business, or public service terms. However, when this happened creativity did not simply disappear from view. On the contrary, architects talked at length about how it had been 'engulfed', 'squeezed out', and 'eclipsed' by the pressures of the day. (Cohen et al., 2005: 792)

In everyday work life, creative endeavours are never abandoned altogether but are rather vanishing slowly as everyday matters are filling up the workday.

In their everyday work, architects are surrounded by images and pictures of buildings and built environments, either published in the architecture press (including publications such as Architecture Review or Details) or on the Internet (virtually all architect offices publish their finished project on-line to promote their brand), and it is easy for them to get the impression that all things novel and exciting are taking place elsewhere and not where they happen to work. In addition, the entire professional ideology (Strauss et al., 1964; Schleef, 2006) is underlining the creative capacity of the practising architects; architects are by definition creative and have the moral obligation to exploit such creative potentials. Since the semi-formal ideology of creativity, effectively buttressed by the various media (journals, Internet, etc.) used in the profession is at times clashing with the everyday work life experience in the actual office, there is a discrepancy between expectation on creative selffulfillment through architect practices and the actual everyday work. This discrepancy is dealt with in various ways, for example, through general complaints about lack of 'risktaking' to more cynical remarks about the degrading of the architect profession or the inability of the broader publics to fully appreciate qualitative architecture. In the next section, a study of a major Scandinavian architect office is reported, emphasizing the creativity of the profession and how the individual architects are dealing with the expectations on them to maintain and nourish their creativity.

\section{Method}

Scandinavian Architect Office (SAO) is a major actor in the Scandinavian architecture industry. The company has about 10 offices in Sweden and Denmark and is owned by about 100 partners among its total of 500 employees. The company was founded in 1951 and has grown organically over time through mergers and acquisitions. SAO is a credible and prestigious actor in the field and has recently won a number of major competitions and contracts. The company is positioning itself as an office having a broad range of competencies in-house including architects, landscape designers, interior decorators, construction engineers, furniture designers and project leaders, and is therefore capable of providing both specialist services but also integrated projects comprising many competencies.

The present study is part of a larger research programme aimed at identifying arenas and mechanisms for the sharing of knowledge and know-how in the construction industry. SAO was chosen as one out of four studies because it had a reputation for taking the issue of knowledge sharing seriously and had implemented a formal system for sharing knowledge between functional domains and over geographical boundaries. The knowledge management officer of the firm helped arrange interviews with 14 co-workers (architects, interior decorators, civil engineers) including himself. Ten co-workers were interviewed at the head office located in a major Scandinavian city and four co-workers were interviewed in a smaller office in Southern Sweden. The interviewees, seven women and seven men, were selected on the basis of the ideal of 'representativity' in terms of formal education, age, organizational tenure, gender and formal position in the firm, and had an organizational tenure ranging from one to 29 years. Being a relative small study, it was not possible to achieve the positivist ideal of a full representation of the firm, but the sample did include virtually all categories of co-workers at SAO. The interviews were semi-structured and 
open-ended. An interview guide was used to structure the interviews. All interviews were tape-recorded and transcribed by one of the researchers. Two senior researchers, both with significant experience of studying the construction industry, conducted all interviews but one. Interviews lasted about one hour.

The transcribed interviews were coded through an open-coded procedure, that is, interview excerpts were structured under different labels. For example, the labels addressed issues such as 'day-to-day work practice', 'attitudes towards work', 'ambitions and aspirations', and so forth. On basis of these categories, the interview excerpts were used to 'emplot' the empirical material (White, 1978), that is, to structure interview excerpts into a credible storyline that makes sense to the reader.

\section{Creativity and its Alleged Lacking in Architecture Work}

Architects tend to have a somewhat mixed image of their own position as creative professionals. On the one hand, they think of themselves as the professional group that needs to safeguard aesthetic virtues and qualities and negotiate trade-offs between supposedly costly design and production factors; on the other hand, they conceive of themselves as a group of professionals who are constantly collaborating with all sorts of stakeholders and therefore are only part of a broader construction process which they are capable of influencing only marginally. While most architects are aware of the harsh reality of the construction industry and the need for keeping costs down, they still maintain that they need to defend aesthetic qualities. 'The whole profession is about exploring new grounds, even though it is a slow process. To advance a little bit forward', one of the architects at SAO argued. Another architect in a top management position emphasizes this ambition to create novel solutions, preferably not previously seen: 'The ambition is always to "produce what no one ever seen before". That is part of the architect's role. When we browse these journals, we are looking for interesting attitudes and ideas on how to explore the problem'. Other interviewees addressed the educational challenges involved in explaining and defending the architect's skills: 'It is complicated to categorize architectural knowledge. What is it really? Here, we still have a problem to define what architects do, what kind of specific knowledge they can offer. This is an attempt to connect people and tacit knowledge and articulate it in discussions and seminars'
(Architect, SAO). What was especially cumbersome was the idiosyncratic combination of aesthetic and technical know-how:

The architecture profession is a bit special ... combining both technical and artistic features... The classical view is that the more clear-cut engineering position uses knowledge that are verified while for us, in our profession, there are components of intuitive knowledge or knowledge that are entrenched or trained. I do not know if this is true but it is the classic view ... Nevertheless, it is an issue in the industry as such because I think we have rather poor mechanisms for organized knowledge sharing. (Architect, SAO)

Architects thus struggled to both justify their expertise and their domain of jurisdiction in the construction process. This included the educational challenge of explaining to other stakeholders how they were capable of balancing aesthetic, technical and economic concerns in the specific project.

\section{Ambitions and Aspirations}

Virtually all architects made use of photos and images produced by other offices as a source of inspiration in their work. They were therefore constantly exposed to work of colleagues and were widely aware of the latest contributions in the field of architecture. In their dayto-day work, working with, for instance, public sector organizations such as health care institutions (i.e., hospitals, day-care institutions), there was comparatively little room for 'creative solutions' to perceived problems. Instead, the functionality of the building was emphasized. Even though the architects were aware of the budget limitations and other practical conditions, they tended to deplore the relatively limited interest for design-related matters: 'At times', one architect argued, 'you need to abandon the design ambitions. It is very much about the function... What the client asks for is not always the form. In most cases, these are no prestige projects in that respect; there is no brand to be promoted but instead other qualities are valued'. He continued:

We think this is a 'creative profession' with 'creative co-workers having their own view of things', and so forth. Not so. There are so many trends; you struggle quite a bit with that, I suppose. I think we all do. It is so easy to find something that looks good, and then you would like to do the same thing. (Architect, SAO)

On the one hand, an abundance of aesthetically appealing projects delivered by a variety 
of European architect offices, and on the other, the actual assignments offered by the local authorities. Architects tended to think that there is a potential for creating even more sophisticated and aesthetically interesting buildings than is the case for the time being. Several of the architects were concerned that there was too little 'experimentation' and 'discussion' going on at SAO and they pointed at the perils of relying on past achievements. One of the more senior architects argued: 'A major office like ours needs to be careful to balance our portfolio of experiences and curiosity. Otherwise, we are digging our own grave and become dead boring'. Among the various explanations for the gradual loss of more experimental thinking was the fierce pace of work over the last few years and a constant flow of incoming assignments: 'It is a high pace [of the work]. The last two years have been hysterical. Then you may have the energy to think a creative thought but you do not have the energy to mobilize the organization that is needed to turn it into an actual event'.

Another architect pointed at the lack of slack in the organization. 'We report every single hour we work here, you cannot write "five hours of research" but you need to apply for research money through the foundation [an internal research fund at SAO] ... It just doesn't work like that. As a rule we report $100 \%$ of our work time and that is a rather stressful work life.' Being preoccupied with incoming work, some of the architects deplored the loss of more innovative and creative discussions and elaborations: 'This will for experimentation, it is far too small. If I can make a wish for this office, then I think we should communicate much more through experiments, with materials, through testing', the architect continued. Another co-worker, a civil engineer, claimed that the lack of slack leads to a form of path-dependency that is very much in opposition with the professional architect's ambition to create new solutions for every new assignment: 'You easily use standard solutions... You don't look at things with a fresh eye ... We have discussed using "brainstorming sessions" addressing problems...But it is quite hard when you're busy and have a problem to have the time for everything'.

This adherence to solutions already used in real life settings was conceived of as being only a marginal problem for the clients but for the co-workers at SAO, it was generally thought that the co-workers were 'not capable of developing either the projects or ourselves in the manner we would like to' (Civil engineer, $\mathrm{SAO}$ ). For instance, one of the leadership challenges for some of the architects in management positions was to protect their subordinates, in many cases newly graduated architects with limited work experience, from losing their 'creative edge' and their ambition to create new and innovative buildings. Individuals with such 'special competencies' - as one of the group leaders put it - should be encouraged not to succumb to architectural clichés and ready-made off-the-shelf solutions. In general, the architect's relatively subordinate position vis-à-vis the contractors was a source of concern for the architects:

The contractor has a significant power and that means that we are not always getting access to the feedback of knowledge... In many cases, it is complicated to monitor the process and the changes that occur. In that respect, our role as architects is at times quite weak ... that is frustrating. It is very much about defending the basic idea, the purpose of the project, throughout all costcuts and budget reductions. (Architect, $\mathrm{SAO})$

The perceived effect of this relative unequal distribution of power in the construction industry leads to what one of the interviewees referred to as a 'continuous struggle between money and aesthetics' - a defence of the aesthetic qualities of a building or other built environment:

I do not know how to put it, but it is a strenuous fight to all the time defend the aesthetic and architectural values and the details, and so forth. And then you know that in the end, the contractor comes with a solution that is uglier and half as expensive and promotes the idea successfully for the client, and then the whole concept is gone and things become, we think, uglier. (Civil engineer)

In many cases, architects saw their innovative and creative solutions being abandoned in favour of some cheaper alternative, reducing the production costs, but at the same time altering the very idea, 'the content', of the building. Needless to say, architects strongly disliked being sidelined in such a manner.

\section{Keeping up the Spirit}

In general, the architects and other co-workers at SAO were very fond of their work and appreciated the variety of assignments they were given. They were comparatively less enthusiastic about the pace of work and the loss of more experimental work. However, competitions served as one of the arenas were new and innovative thinking could be executed. Virtually all architects and other 
co-workers claimed competitions played an important role in the profession and for the office in terms of providing a space for experimentation and collaboration in new constellations. However, one of the younger architects with only a few years of experience from the industry but strongly dedicated to his profession was critical of the competitions as being too much focused on 'actually winning' the competitions rather than 'stretching the boundaries' for what could be done. For instance, he suggested, rather than following the programme (i.e., the written formal instructions provided by the clients arranging the competition) in detail, one should try to reformulate and rearticulate the programme before engaging with actual architectural solutions. That is, rather than merely delving into a perceived and ready-made problem, the competitions could be used to think outside of the regular boxes of the profession. The young architect thus called for a more playful relationship to the competitions; rather than winning it is important to further develop the competencies of the co-workers of SAO, he claimed.

Being empowered by the work of prestigious and highly esteemed offices such as OMA in Holland and a number of Swiss architect offices, some of the younger architects were very dedicated to the advancement of the profession. After years of professional work, not all of the more senior architects shared such ambitions even though they had a great deal of sympathy for this enthusiasm. One of the more senior architects reflected on his professional developments:

I graduated in '86. Back then I studied art history in my leisure time and took courses in architecture history and architecture theory but since then things have changed. The work is taking over more and more. I have turned into one of those tired architects that I noticed when I was 25 years old myself. (Architect, SAO)

While some of the younger architects spend a substantial part of their leisure time thinking about and visiting built architecture and elaborating with scale models, some of the more senior architects did not have that time but had to 'go pick up the kids at the kindergarten by four-thirty'. 'Keeping up the spirit' of creativity and novel thinking was therefore not always a top priority for this category of architects. At the same time, as one of the senior architects agued, it is to some extent a matter of attitude: 'It is an attitude, I'd say ... An attitude towards the job... Either you lose it or you move on to face new situations' (Architect, SAO). No matter how you explain some individuals' behaviour and preferences over time, there is still a strong sense among architects of a professional imperative to maintain creativity and to take responsibility for the aesthetic values of the built environment.

\section{Discussion}

The present study shows that in the case of SAO, architects were aware of their role and position within the construction industry and recognized the need for collaborating closely with clients, end-users, construction company representatives and other relevant stakeholders. On the other hand, many of the architects argued that they did not invest enough time to fully exploit and explore their individual and collective creative potentials. Rather than deploring the position and status of the architect in the construction industry and in society more broadly, several of the architects addressed this inadequate use of creative potentials in terms of being a management or leadership issue. Some of the architects explicitly claimed that SAO should engage in more activities supporting a creative mindset and novel ways of thinking. Traditionally, architectural competitions have served the role of the 'laboratory' in which novel ideas are elaborated on or tested. However, some of the architects thought that the competitions were increasingly becoming all-too-important business opportunities that could not be jeopardized by experimental thinking. As a consequence, one of the few domains where genuine creative thinking could be executed was to some extent increasingly reserved for more tempered contributions. However, internal competitions were at times organized by $\mathrm{SAO}$, potentially playing the same role as the full-scale competitions. The study also suggests that in some cases, architects start their careers with the ambition to provide new and creative solutions to housing and built environment problems, but that after years of experience they tend to develop a somewhat more realistic view of what it is possible to accomplish. However, the architect's career trajectory does not necessarily lead from being 'young and positive' to 'old and cynical'; in many cases, older architects have acquired adequate experience helping them to participate successfully in competitions and convincing clients of the value of qualitative architecture. The careers of architects are, like in many other professions (e.g., the sciences) portfolio careers, unfolding as a series of events and accomplishments and emphasizing what has been produced. At the same time, 
architects are by and large subject to the same mechanisms as scientists, that is, what Robert Merton speaks of as the 'Matthew effect' where the eminent architect/scientist gets proportionately greater credit for their contributions while the relatively unknown architect/ scientist gets disproportionately little credit.

Being creative and exploring and exploiting one's creative skills are, however, a major challenge for architects. Compared with the study by Cohen et al. (2005), the interlocutors at SAO also perceived themselves as having multiple roles and they were therefore always struggling to balance these different roles. For instance, some of the senior architects interviewed were also group leaders, responsible for the management and leadership of a team of architects at the office and therefore had a formal 'business people' role. In the case of one of the senior male architects, since a number of years back heavily involved in various hospital projects, the public servant role was always implied in his assignments and in many cases his creative ambitions clashed with practical, juridical and financial aspects that had to be taken into account. The architects were therefore enduring a daily struggle to maintain their creative ambitions.

While many creative industries are anchored in their more or less explicit ideology of creativity, that is, neophytes are attracted by the sense of excitement and 'aura' of certain industries (Nixon, 2005) including the advertising industry, the fashion industry, the various 'art worlds', and architect work, in day-to-day practice, many actors are likely to endure a sense of being unable to exploit their perceived full potential. Only a small elite of 'starchitects' (Jones, 2006) such as Norman Foster and Frank O. Gehry may take advantage of the resources needed to operate freely in the field of architect work. For the vast majority, day-to-day work is characterized by some exciting moments, a good deal of interesting routine work and some less rewarding or even boring activities. Still, living under the burden of being creative and innovative may be regarded as what to some extent is undermining a proper evaluation of one's actual achievements. As has been pointed out by numerous social scientists and psychologists, one's sense of value and status is a thoroughly relational matter; my sense of worth is never isolated from how others are appreciated and valued but is instead a direct effect of such comparisons (e.g., Shotter \& Billig, 1998; Sluss \& Ashforth, 2007). In industries characterized by creative components, the actors need to be capable of managing their own position and status in relationship to other actors. That is, in our case, the architects engaging in day-to-day work are always aware that there are other projects running that may be more prestigious and that may attain more attention. Architects are in other words managing their 'creativity capital' which ultimately locates them in a certain position in their professional field. For instance, winning prestigious competitions commonly (but not always) increases the individual architect's creative capital but also a non-winning contribution to the field being valued by peers may add to the stock of creative capital. Taken together, creativity is an intangible and highly abstract resource being mobilized when architects are negotiating their relative positions within their professional fields. Creativity is therefore not only an ideology in the abstract sense of the term, as some kind of transcendental belief or set of assumptions, but is instead what is immediately manifested in the visual artefacts being generated in the architect work, in the 3D CAD images, the sketches, the scale models, and the blueprints produced. Creativity is what is always present in what is produced in architect's practice; it is inherent to the work, it is a constitutive component that yet needs to be decoded by the trained professional eye. Given this central importance of the ability to realize one's creative potential, it is little wonder that architects are expressing their concern over diminishing creative spaces in their daily work. For architects, the insistence on using one's creativity is then no empty gesture or an attempt to safeguard prestige vis-à-vis other professional groups but is rather a form of reproduction of the institutional setting of their professional field. Architects do not insist on the need for creativity to convince the broader public of their value but rather to enable the accumulation of creative capital for the individual actor. As has been pointed out by several students of professional groups (e.g., Larson, 1977), professions are inward oriented rather than oriented towards clients or other end-users; professional status is engendered by peer recognition rather than outsiders' opinions.

\section{Conclusion}

The study of SAO suggests that many of the architects were critical of the lack of creative thinking and critical debates and discussion regarding the nature of their work and the future of the architect profession. Largely in line with previous studies of both creative industries and architect work (e.g., Cohen et al., 2005), the study shows that architects and other groups of experts in SAO tended to think of their work as always under the threat 
of losing its creative core. Architects tend to serve many complementary roles but their principal professional identity is anchored in the idea that architect work is essentially a creative undertaking, capable of bridging a number of competencies and interests into a functional unity. In addition, there are aesthetic skills and virtues involved in architect work that need to be attended to and protected from other interests and concerns. However, even though it is meaningful to conceive of architect work as a form of creative work embedded in aesthetic and sensible knowledge, architects are less exposed to the genuine uncertainty that for instance theatre and the music industry is enduring (Dempsey, 2006); architects are still protected by entry barriers such as the demands for formal educational credentials and have managed relatively well to protect their interests and domains of jurisdiction, and today they play a central role in the temporal constellations being assembled in the construction industry as new construction projects are started. For the architects, creativity is rather threatened by the day-to-day routines, which gradually and at times unnoticed push the creative activities into the margins of the work, thereby slowly rendering the daily work devoid of the highly praised creative endeavours.

\section{References}

Amabile, T.M. (1997) Motivating Creativity in Organizations: On Doing What You Love and Loving What You Do. California Management Review, 40, 39-58.

Amabile, T.M. (1999) How to Kill Creativity. Harvard Business Review, September-October, 77-87.

Amabile, T.M., Conti, R., Coon, H., Lasenby, J. and Herron, M. (1996) Assessing the Work Environment for Creativity. Academy of Management Journal, 39, 1154-84.

Amabile, T.M., Schatzel, E.A., Moneta, G.B. and Kramer, S.J. (2004) Leader Behaviours and the Work Environment for Creativity. Perceived Leader Support. Leadership Quarterly, 15, 5-32.

Andreu, I.C. and Oreszczyn, T. (2004) Architects Need Environmental Feedback. Building Research and Information, 32, 313-28.

Andriopoulos, C. (2001) Determinants of Organisational Creativity: A Literature Review. Management Decision, 39, 834-40.

Basadur, M. (2004) Leading Others to Think Innovatively Together. Creative Leadership. Leadership Quarterly, 15, 103-21.

Blau, J.R. (1984) Architects and Firms: A Sociological Perspective on Architectural Practice. The MIT Press, Cambridge, MA.

Boland, R.J., Lyytinen, K. and Yoo, Y. (2007) Wakes of Innovation in Project Networks: The Case of
Digital 3-D Representation in Architecture, Engineering, and Construction. Organization Science, 18, 631-47.

Bourdieu, P. (1993) The Field of Cultural Production: Essays on Art and Literature, edited by Randall Johnson. Polity Press, Cambridge.

Bryman, A. (1992) Charisma and Leadership in Organizations. Sage, London.

Caves, R.E. (2000) Creative Industries. Harvard University Press, Cambridge, MA.

Cohen, L., Wilkinson, A., Arnold, J. and Finn, R. (2005) Remember I'm the Bloody Architect! Architects, Organizations and Discourses of Professions. Work, Employment and Society, 19, 77596.

Cuff, D. (1991) Architecture: The Story of Practice. The MIT Press, Cambridge, MA.

DCMS (Department for Culture, Media and Sport) (1998) Creative Industries Mapping Document. URL http:/ / www.culture.gov.uk [accessed on 4 December 2008].

DCMS (Department for Culture, Media and Sport) (2001) Creative Industries Mapping Document, $2^{\text {nd }}$ edn. URL http://www.culture.gov.uk [accessed on 4 December 2008].

Dempsey, A.M. (2006) Managing Uncertainty in Creative Industries: Lessons from Jerry Springer the Opera. Creativity and Innovation Management, 15, 224-32.

Ewenstein, B. and Whyte, J. (2007) Beyond Words: Aesthetic Knowledge and Knowing in Organizations. Organization Studies, 28, 689-708.

Florida, R. (2002) The Rise of the Creative Class. Basic Books, New York.

Gutman, R. (1988) Architectural Practice: A Critical View. Princeton Architectural Press, Princeton, NJ.

Ivory, C. (2004) Client, User, and Architect Interactions in Construction: Implications for Analyzing Innovative Outcomes from User-Producer Interactions in Projects. Technology Analysis E Strategic Management, 16, 495-508.

Jeffcut, P. (2000) Management and the Creative Industries. Studies in Cultures, Organizations and Societies, 6, 123-7.

Jones, C., Hesterly, W.S., Fladmoe-Lindquist, K. and Borgatti, S.P. (1998) Professional Service Constellations: How Strategies and Capabilities Influence Collaborative. Organization Science, 9, 396-410.

Jones, P.R. (2006) The Sociology of Architecture and the Politics of Building: The Discursive Construction of Ground Zero. Sociology, 40, 549-65.

Knight, F.H. (1921) Risk, Uncertainty, and Profit. Houghton Mifflin, Boston, MA.

Larson, M.S. (1977) The Rise of Professionalism: A Sociological Analysis. University of California Press, Berkeley, CA.

Menger, P.-M. (1999) Artistic Labour Markets and Careers. Annual Review of Sociology, 25, 541-74.

Miller, W.C. (1999) Flash of Brilliance: Inspiring Creativity Where You Work. Perseus Books, Reading, MA.

Mumford, M.D., Scott, G.M., Gaddis, B. and Strange J.M. (2002) Leading Creative People. Orchestrating Expertise and Relationships. Leadership Quarterly, 13, 705-50. 
Nixon, S. (2005) Advertisement Culture. Sage, London.

Oldham, G.R. and Cummings, A. (1996) Employee Creativity: Personal and Contextual Factors at Work. Academy of Management Review, 39, 607-34.

Osborne, T. (2003) Against 'Creativity': A Philistine Rant. Economy and Society, 32, 507-25.

Rickards, T. and Moger, S. (2000) Creative Leadership Processes in Project Team Development: An Alternative to Tuckman's Stage Model. British Journal of Management, 11, 273-83.

Roodhouse, S. (2006) The Unreliability of Cultural Management Information: Defining the Visual Arts. Journal of Arts Management, Law, and Society, $36,48-65$.

Schleef, D.J. (2006) Managing Elites: Professional Socialization in Law and Business Schools. Rowman \& Littlefield, Lanham, MD.

Schumann, P.A. Jr. (1993) Creativity and Innovation in Large Organization. In Kuhn, R.L. (ed.), Generating Creativity and Innovation in Large Bureaucracies. Quorum Books, Westport, CT, 11130.

Schumpeter, J.A. (1942) Capitalism, Socialism, and Democracy. Harper \& Row, New York.

Shalley, C.E. and Gilson, L.L. (2004) What Leaders Need To Know: A Review of Social and Contextual Factors That Can Foster or Hinder Creativity. Leadership Quarterly, 15, 33-53.

Shin, S.J. and Zhou, J. (2003) Transformational Leadership, Conservation, and Creativity: Evidence from Korea. Academy of Management Journal, 46, 703-14.

Shotter, J. and Billig, M. (1998) A Bakhtinian Psychology: From Out of the Heads of the Individuals and Into the Dialogues Between Them. In Bell, M.M. and Gardiner, M. (eds.), Bakhtin and the Human Sciences. Sage, Thousand Oaks, CA.

Sluss, D.M. and Ashforth, B.E. (2007) Relational Identity and Identification: Defining Ourselves Through Work Relationships. Academy of Management Review, 32, 9-32.

Strati, A. (2007) Sensible Knowledge and PracticeBased Learning. Management Learning, 38, 61-77.

Strauss A., Schatzman, L., Bucher, R., Ehrlich, D. and Sabshin, M. (1964) Psychiatric Ideologies and Institutions, 2nd edn. Transaction Books, London.

Styhre, A. and Sundgren, M. (2005) Managing Creativity in Organizations: Critique and Practices. Palgrave, Basingstoke.
Taylor, S.S. and Hansen, H. (2005) Finding Form: Looking at the Field of Organizational Aesthetics. Journal of Management Studies, 42, 1211-31.

Unsworth, K. (2001) Unpacking Creativity. Academy of Management Review, 26, 289-97.

Unwin, S. (2007) Analysing Architecture Through Drawing. Building Research and Information, 35, 101-10.

Weber, M. (1948) Science as a Vocation. In Gerth, H.H. and Wright Mills, C. (eds.), From Max Weber: Essays in Sociology. Routledge and Kegan Paul, London, 129-56.

White, H. (1978) Tropics of Discourse: Essays in Cultural Criticism. The Johns Hopkins University Press, Baltimore.

Winch, G. and Schneider, E. (1993) Managing the Knowledge-Based Organization. The Case of Architectural Practice. Journal of Management Studies, 30, 923-37.

Yaneva, A. (2005) Scaling Up and Down: Extraction Trails in Architectural Design. Social Studies of Science, 35, 867-94.

Alexander Styhre (Alexander.Styhre@ chalmers.se) is Professor and Chair of Operations Management at Chalmers University of Technology, Gothenburg, Sweden. He received his $\mathrm{PhD}$ from Lund University. Alexander has published widely in journals concerned with innovation and knowledge-intensive organizations. He is the author of 13 books, including most recently Managing Knowledge in the Construction Industry (Routledge, 2009), Science-Based Innovation (Palgrave, 2008) and, Perception and Organization (Palgrave, 2008).

Pernilla Gluch is Senior Lecturer in Construction Management at Chalmers University of Technology, Gothenburg, Sweden, from where she received her PhD. Pernilla's research interests concern organizational and social structures and their influence on how strategic change, especially sustainable development, is dealt with in the construction process. 